Table 2

F Values Derived from Analyses of Variance of Avoidance Acquisition Measures

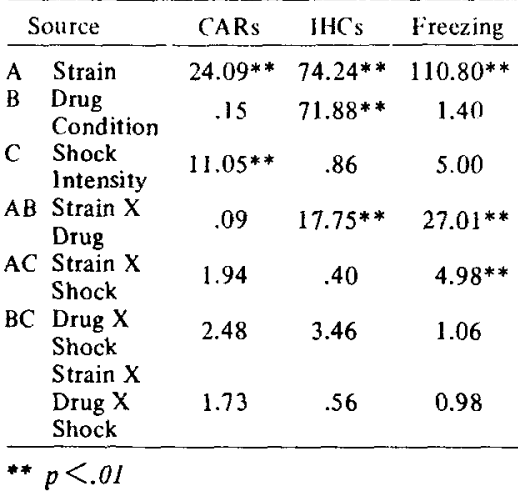

the highest 1,500-microampere intensity than at the 50,300 , or 800 levels $(\mathrm{p}<.01)$.

Significant interaction effects were found for both intertrial hurdle crossings (IHCs) and freezing behavior. Analysis of the simple main effects of the Drug by Strain interaction for IHCs indicated no differential effects on the strains while under drug, but under placebo, MRs had more IHCs than MNRs ( $F=4.21, p<.01)$. While drug condition did not affect the number of IHCs emitted by the MNRs, the MRs gave more IHCs under placebo than under amobarbital $(\mathrm{F}=5.60, \mathrm{p}<.01)$.

In freezing behavior, the Drug by Strain interaction was due to less freezing in the MNRs in the drug as compared to the placebo condition, while MRs actually showed more freezing under the drug. The Strain by Shock Intensity interaction for freezing was due to greater freezing by the MNRs at the three higher intensities than at the lowest, while there was no difference in freezing scores for the MRs over the various intensities.

While amobarbital had no demonstrable effect on CAR scores, it was effective in increasing IHCs and in attenuating freezing behavior in the MNR strain. The failure of amobarbital to increase general activity and lower freezing in the more emotional MR strain was a surprising result and is inconsistent with our previous findings, i.e., that use of amobarbital with Wistar rats selected as "high" emotionals increased both avoidance responses and hurdle crossings while decreasing freezing. In the present study, freezing of the more highly emotional strain actually tended to increase with amobarbital.

At this point, speculation as to why amobarbital failed to have an effect seems warranted. This drug appears to enhance avoidance performance only in those Ss giving a relatively low number of CARs under placebo. In comparison to other experimental populations termed "high emotional" and tested for differential drug effects in our laboratory (high-emotional Wistars, Tryon S1s), the MRs are relatively proficient avoiders. It may be that the drug did not affect MR avoidances simply because they did not "need" the drug since they were already performing at their optimal levels.

In summary, although amobarbital did alter some aspects of behavior of the Maudsley strains differentially during avoidance conditioning, the results were not in the direction anticipated on the basis of past findings.

\section{REFERENCES}

BROADHURST, P. L. The hereditary base for the action of drugs on animal behavior. In $\mathrm{H}$. Steinberg (Ed.), Animal behavior and druo action. Boston: Little, Brown, 1964. Pp. 224-237.

KAMANO, D. K., MARTIN, L. K., \& POWELL. B. J. Avoidance response acquisition and am oba r bital dosage levels. Psychopharmacologia, 1966, 8, 319-323.

KRIECKHAUS, E. E., MILLER, N. E., \& ZIMMERMAN, P. Reduction of freezing behavior and improvement of shock avoidance by d-amphetaminc. Journal of Comparative \& Physiological Psychology, 1965, 60, 36-40.

MARTIN, L. K., POWLLL, B. J., \& KAMANO, D. K. Effects of amobarbital sodium on avoidance performances of rats differing in emotionality. Proceedings of the 74th Annual Convention of the American Psychological Association, 1966, 125-126.

MARTIN, L. K., POWELL, B. J., \& KAMANO, $D$. K. Mediation of shock and drug-produced effects on avoidance responding. Psychonomic Science, 1967, 9, 3-4.

POWELL, B. J. Prediction of drug action: Elimination of error through emotionality. Proceedings of the 75 th Annual Convention of the American Psychological Association, 1967, 69-70.

POWELL, B. J., MARTIN, L. K., \& KAMANO, D. K. Effects of amobarbital sodium and meprobamate on acquisition of conditioned avoidance. Psychological Reports, 1965, 17, 691-694.

POWELL, B. J., MARTIN, L. K., \& KAMANO, D. K. Relationship between emotionality, drug effects, and avoidance responses in Tryon $S_{1}$ and $S_{3}$ strains. Canadian Journal of Psychology, 1967, 21, 294-300.

WINER, B. 1. Statistical principles in experimental design. New York; McGraw-Hill, 1962.

\section{NOTE}

1. Now at Washington University and Malcolm Bliss Mental Health Center, St. Louis, Missouri.

\title{
Aspects of deprivation and allowance for grow th in young rats
}

\section{MAXWELL TAYLOR, University Liverpool, Liverpool, England}

A replication of earlier work on the straight-line log-reciprocal growth function is reported. Negative results were achieved when the line of best fit, derived from an earlier log-reciprocal growth function in the same rat, was used to predict subsequent allowance for growth in deprivation and recovery of weight after deprivation.

Techniques for controlling deprivation in rats can be broadly classified into two categories: systematic restriction of access to food for some specified period or reduction to some percentage of free-feeding weight, and maintaining the rat at that weight, within certain arbitrarily defined limits. Difficulties arise, however, when either of the above procedures are applied to young, growing rats, where some allowance for growth is necessary if the relationship between deprived weight and free-feeding weight is to be in some sense constant.

Systematic restriction of access to food superficially appears to overcome the above difficulty in that within the access-to-food time limit, any amount of food may be consumed, but the procedire in general suffers from several severe difficulties (Bolles, 1967; Kaplan et al, 1956), and in terms of control of body weight, the above technique is preferable.

Defining deprivation in terms of percentage body weight appears to be satisfactory for adult rats, but no clear procedure exists for calculating the necessary allowance for growth in young rats. There have been two general approaches to this problem: either an increment, taking growth into account, may be added to the initial percentage weight (Pierrel, 1958) or the potential free-feeding weight, making the necessary allowance for growth, may be calculated, and the necessary adjustment then made in the percentage body weight (Kaplan et al, 

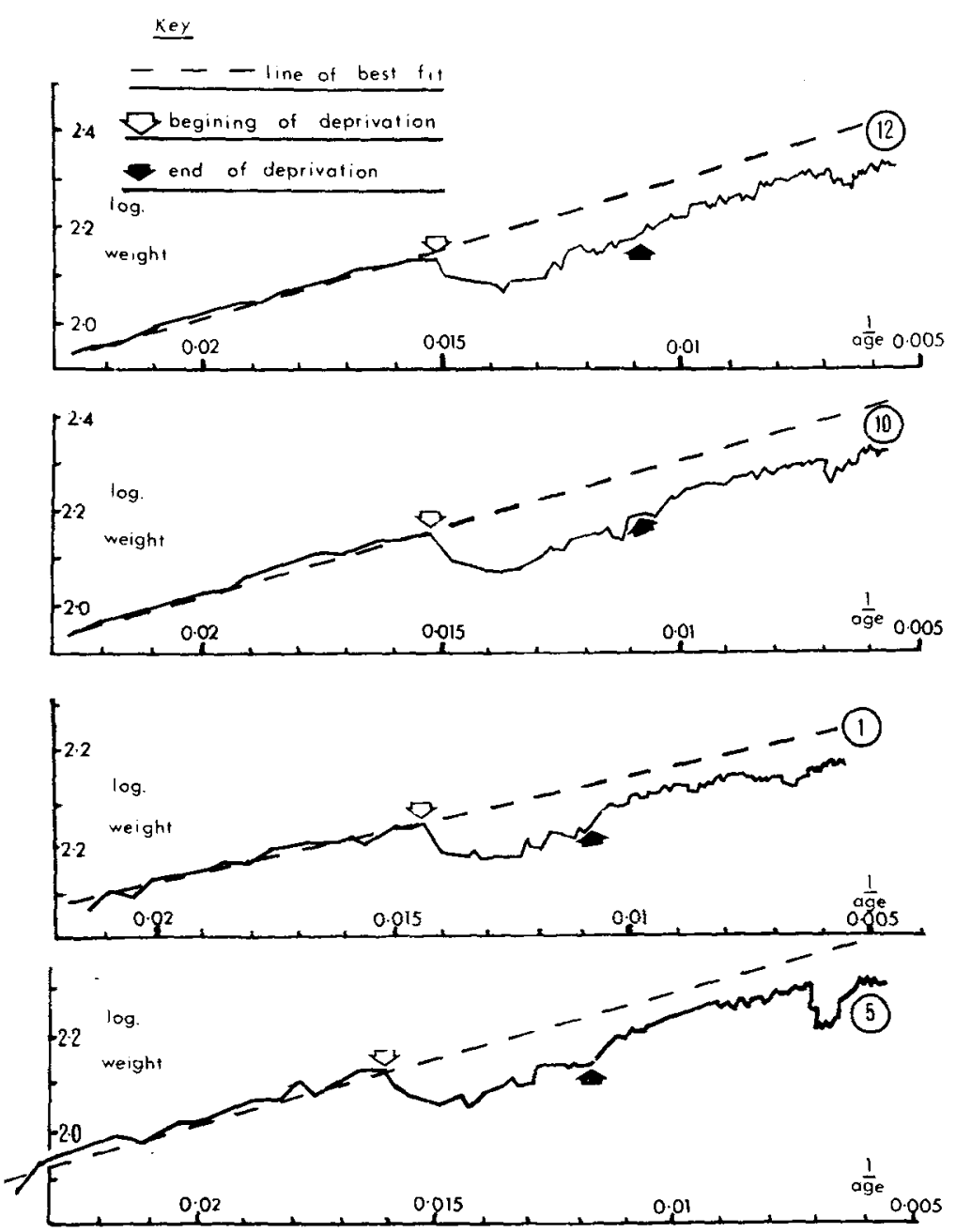

1959; Kaplan \& Kaplan, 1965; Bolles, 1967). These above procedures are not always suitable, however, for the small laboratory not breeding its own stock, and, because they deal largely with groups of animals, they are not particularly suited for use in single-organism research.

A technique does exist, however, which appears to satisfy the above requirements. It was outlined by Zucker (1953) and consists of plotting, for individual rats, the logarithm of the weight against the reciprocal of the age, thereby creating what Zucker claims would be a "straight line growth function." From such a growth function, it is clear that predictions of future potential free-feeding weights can be made, from which potential percentage weights can be calculated, thereby making the necessary allowance for growth. The line of best fit (Edwards, 1963) has been used to produce predictions of potential free-feeding weights.

Taylor (1969) reported preliminary work, replicating some of Zucker's findings, using Lister hooded rats at three age ranges. It was found that, for the two adequate for deprivation control.
Fig. 1. Log-reciprocal growth function, lines of best fit, and deprivation.

deprived, were adjusted daily, in accordance with predictions made from the line of best fit. At age 85 days, the animals were again given unlimited access to food, daily weighings still being taken until age 174 days.

Figure 1 presents the log-reciprocal growth functions and lines of best fit for all four animals. The adequacy of the line of best fit, as derived from the log-reciprocal growth function from age range 40-62 days, and as measured by its ability to predict subsequent growth, can be seen to be rather poor, thus confirming the tentative results of Taylor (1969). The weight curves in Taylor (1969) show considerable similarity to those obtained in this study. On no occasion did the actual weight of any rat, after deprivation, come within $5 \%$ of the predicted free-feeding weight, as calculated from the line of best fit, and on only four occasions for Rat 5 and 11 for Rat 1 did the free-feeding weight come within $10 \%$ of the predicted free-feeding weight; the latter never occurred for the other animals. The ultimate free-feeding weights of these rats fell within the normal range of weights of undeprived rats in this colony, thus suggesting that deprivation at this age range had no deleterious effects on subsequent growth.

Such errors in prediction are clearly unacceptable, and it must therefore be concluded that, for rats in this situation and fed on this diet, the line of best fit shorter age ranges (28-62 days and 44-72 derived from the log-reciprocal growth days), the log-reciprocal weights of function is not an adequate predictor of free-feeding rats quite closely subsequent growth. approximated the appropriate line of best fit. However, further animals from age range 44-72 days were subsequently weighed at age range 136-168 days. It was found that the lines of best fit appropriate to age range $44-72$ days, for these animals, was a poor predictor of subsequent growth. Further investigations were then undertaken to see if this technique was

Four female Lister hooded rats, individually caged and kept at a constant temperature, were weighed daily, with unlimited access to food, 1 from ages 40 to 62 days. The log-reciprocal growth functions were individually plotted, and lines of best fit were calculated. At age 62 days, all rats were placed on a deprivation schedule aimed at reducing the rats' weights to $80 \%$ of the potential free-feeding weights, as calculated from extrapolation of the line of best fit; it is clear, therefore, that the $80 \%$ target weights to which the animals were

\section{REFERENCES}

BOLLES, R. C. Theory of motivation. New York: Harper International Edition, 1967.

EDWARDS, A. L. Statistical methods for the behavioral sciences. New York: Holt, Rinehart \& Winston, 1963.

KAPLAN, M., CAMPBELL, S. L., JOHNSON, L., PAPAMICHAEL, A., SPARE, R., \& WEINBAUM, M. Growth of body weight and manipulation of food motivation. Science, $1959,129,1673-1674$.

KAPLAN, M., \& KAPLAN, E. F. Estimating growth of inbred rats for behavioral and biological studies. Psychological Reports, 1965, 17, 419-423.

PIERREL, R. A generalization gradient for auditory intensity in the rat. Journal of the Experimental Analysis of Behavior, 1, 303-313.

TAYLOR, M. A preliminary report on deprivation and allowance for grow th in young rats. Papers in Psychology, 1969, 3, 20-21.

ZUCKER, L. M. 'Growth criteria' in rat quality: A consideration of heredity, diet and disease. National Vitamin Foundation, 1953, 3-22. NOTE

1. All animals were fed Spittal 4 rat cubes, produced by Compounds Development Unit, Bromborough Port, Che shire, England. 